\section{Care of the Newly Born Infant}

W. S. CRAIG, B.SC., M.D., F.R.C.P., F.L.C.P., F.R.C.S.E., in collaboration with others. Second Edition. Pp. vii +568 , with 262 figures. Edinburgh and London: E. \& S. Livingstone. 1962. 40s.

The second edition of this well-known work should again attract many readers. The book has been brought up to date which has meant the rewriting of some sections and the incorporation of new material. Further additions have been made to the remarkable collection of clinical photographs which adorned to such great advantage the pages of the original volume. Once again no references to medical literature are made by the authors which must be unusual in a work of such size and scope. In spite of a slight change in title it can be said that this treatise, with its continuing emphasis on the practical aspects of infant care, is still primarily designed for midwives and sick children's nurses, both trained and in training. However, general practitioners engaged in obstetrics and doctors dealing with maternity and child health will find it most valuable.

The book is said to be uncontroversial but this is not strictly true as scattered here and there are points which some, at least, may think are of a contentious nature. Let us now consider a few of these at random. Is it really sound practice to ask midwives who are very busy people to wash routinely at birth the hands of all babies because it is alleged to prevent contamination of the infant's own eyes and mouth? Bearing in mind the danger of milk aspiration, should nurses still be encouraged to feed premature infants with a spoon, pipette or 'Belcroy'? Is it strictly correct to say that gangrene of the fingers usually occurs in small babies with a tendency to cold extremities and an unsatisfactory peripheral circulation? Incidentally, the mishap of constriction of a digit by loops of nylon thread from the inside of a mitten, described in the chapter on trauma, might perhaps be more appropriately placed in this section on digital gangrene. Other queries may occur to the critical reader. Thus, in a book so recently revised should not intra-gastric oxygen for neonatal asphyxia be given the coup de grace it surely deserves? Admittedly, the authors state that this method no longer finds favour with them, but so long as it appears in print there will be a tendency for rome to use it. In the section on resuscitative measures and in other parts of the book coramine is suggested as a respiratory stimulant. May not this drug, which we are told sometimes leads to increased neuro-muscular activity, cause brain cell damage in the anoxic state? Possibly its safety lies in its ineffectiveness when given to a collapsed infant by the intra-muscular route. In the new and welcome section on neonatal cold injury we are told the incidence of this disturbance is higher amongst premature infants; this has not been the general experience and the statement will certainly be questioned by some. We are also told here that any urine passed by these babies will have a high albumin content. This finding must be the exception rather than the rule. Lastly, would it not be better to omit the photograph of blood sampling from the superior sagittal sinus, bearing in mind the type of reader for which this work is intended? This rather dangerou每 method of veni-puncture must be very rarely used nowadays, at least south of the Border.

The book reads well and the standard of descriptive writing in the clinical sections is high, the many photo graphs and illustrations contributing to this first-class presentation. There may be some who will think that the colourful account of the newly-born infant of the diabetic mother is more poetic than apposite, but the is an exception to the general lucid style.

These are all small criticisms of a really outstanding book which deserves the popularity it has alread enjoyed in its first impression. Because of the need ff a treatise of this kind one hopes that in the years abead $t$ will be brought up to date through further editiong

\section{Practical Pædiatrics: A Guide for Nurses}

J. M. WATT, M.B., CH.B.(N.z.), M.R.C.P.(LOND.), D.C.H. Pp. I93, with 49 figures. Christchurcf,

New Zealand: N. M. Peryer. 1961. 30s.

This little book for nurses which comes to th country from New Zealand is really outstandingly good. It is well and concisely written and its pages corgtam an unusual amount of common sense. All the impotang things seem to be covered except that spontaneogs

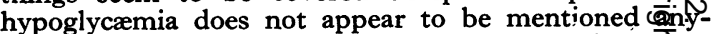
where. However, to offset this deficiency there is $\mathrm{Ca}_{2}$ short account of the emotional repercussions whigh may follow a young child's admission to hospital in twe chapter on behaviour disturbances. This topic, pasticularly the preventive aspects, has probably not hitherto been dealt with in this way in a pædiatfic textbook. The chapter on congenital malformations contains a lucid description of genetics with some goodd illustrations which help to simplify the text here. TRe one on tuberculosis is excellent with some neat lipe drawings of various kinds of intra-thoracic pathology to aid the reader. Infant feeding is well covered in tien pages and it is refreshing in this chapter to read sugh statements as "care must be experienced in giving advice and no inflexible views should be held' and 'infant's digestive powers are by no means incợsiderable'.

The standard of clinical description is generally high but an exception to this statement may be found in that part dealing with the prognosis and treatment $8 \mathrm{f}$ fibro-cystic disease of the pancreas. No reference is made here to the new approach to this hitherto crippling disease. In another part it is a little disappointing to find that the physiological anæmia of young infants As $^{3}$ still attributed to hæmolysis.

The work is well printed and liberally illustrated with diagrams and clinical photographs. It is perhagess a pity at a time when, in this country at least, tobacgo advertising is being discouraged that a well-known brand of cigarettes appears prominently in one of the early photographs.

(D)

In spite of its distinct New Zealand flavour (we regd of such exotic foods as Anchor Brand and Meadoiymaid) this book can be thoroughly recommended to nurses in this country and no less to their teachers. should prove very popular in its country of origin. 